\title{
Haga usted el diagnóstico Primera parte
}

\author{
Angélica Knudson, Nohora Marcela Mendoza, Rubén Santiago Nicholls
}

Grupo de Parasitología, Instituto Nacional de Salud, Bogotá, D.C., Colombia.

Se presenta el caso de una mujer de 29 años de edad con historia de residencia previa en Maputo (Mozambique, África) hasta dos meses antes de la fecha de consulta cuando regresó a Bogotá, Colombia. En esta fecha consultó por presentar un cuadro clínico de tres meses de evolución de períodos de fiebre intermitente que alternaban con períodos asintomáticos. La periodicidad de los picos febriles era irregular (cada 48 a 72 horas) y de predominio nocturno. Además, presentó dorsolumbalgia, orinas de color ámbar oscuro, cefalea, escalofríos, dolores articulares y musculares, sialorrea y diaforesis profusa. La paciente describía, también, sensación de malestar permanente que aunque no le impedía el desarrollo normal de sus actividades cotidianas, sí la hacía sentirse enferma.

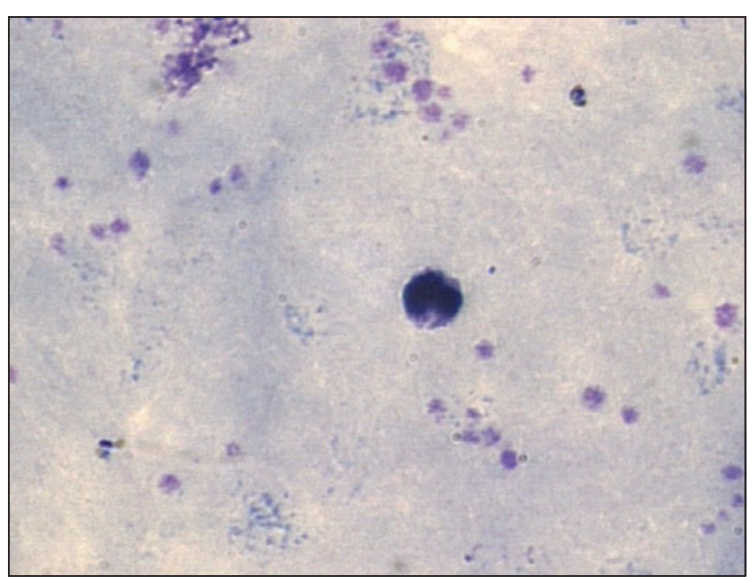

Figura 1.

\section{Correspondencia:}

Angélica Knudson, Laboratorio de Parasitología, Instituto Nacional de Salud, Avenida Calle 26 No. 51-60, Bogotá D.C. Teléfono: (571) 2207700 , extensión 423. parasitologia@ins.gov.co

Recibido: 28/05/04; aceptado: 31/05/04
En el examen físico se encontró palidez mucocutánea leve, discreto tinte ictérico en escleras, con buena hidratación, tensión arterial de 120/80 mm Hg, frecuencia cardíaca de 100 latidos por minuto, frecuencia respiratoria de 20 por minuto y afebril. El único hallazgo en el examen físico fue el dolor abdominal a la palpación con esplenomegalia moderada.

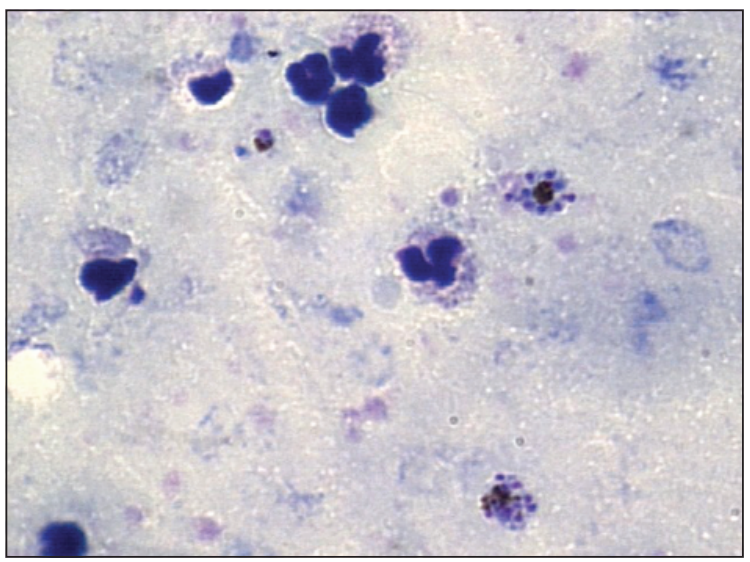

Figura 2.

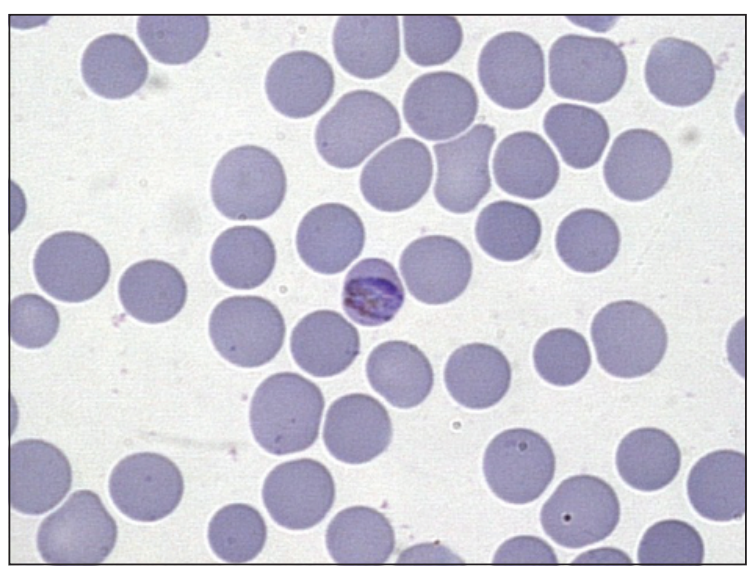

Figura 3. 
Había presentado anteriormente episodios similares mientras vivía en Mozambique, razón por la cual consultó al médico; se le practicaron diferentes exámenes, entre ellos, varias gotas gruesas para identificación de hemoparásitos que fueron negativas. A su llegada a Colombia consultó a otra institución y, con un diagnóstico presuntivo de infección de vías urinarias, le formularon gentamicina más ciprofloxacina.
Consultó al Laboratorio de Parasitología del Instituto Nacional de Salud, en donde se tomaron varias muestras. Las figuras 1 a 3 muestran algunos de los hallazgos.

Preguntas:

1. ¿Cuál es su diagnóstico?

2. ¿Cuál es el tratamiento indicado? 